\title{
Application of Fuzzy Cognitive Mapping for Cognitive Task Analysis in Mechanised Mines
}

\author{
${ }^{1}$ Subrata Maitra, ${ }^{2}$ Debamalya Banerjee \\ l Assistant Professor in Production Engineering, Mallabhum Institute of \\ Techhnology,BrajaradhanagarBishnupur, Bankura 722122 West Bengal,e-mail subrata.712@ rediffmail.com \\ 2 Associate Professor, Department of Production Engineering, Jadavpur University, Raja S.C. Mullick Road \\ , Kolkatta :700032,
}

\begin{abstract}
Man- machine interaction in a mechanized mines involved the excavation of mineral through heavy earth moving machineries and sizing the lump ore of the open cast mines in an overhead crushing, screening and loading (OCSL) plant. Present study proposes a systematic way of analyzing various factors like environmental impact and working problems as the mines are primarily located in remote areas. Selective mining is being done after locating the enriched ore through geological sampling. So the problem involved continuous planning based on the reliability of human factor and contribution of machineries for improving the production to reach the desired target .There are number of natural and operational hazards and decision variables are also too many. Fuzzy cognitive mapping have proven efficient for solving problems in which a number of decision variables and uncontrollable variables are causally interrelated. The system reliability is primarily linked up with human factor engineering to carry out the tasks. Besides failure analysis involved operational performance of various mining machineries and plant machineries.Fuzzy cognitive mapping of the different key activities will enable us to pinpoint the priorities of the operations and available contributions from the angle of machine availability, spare parts supply, manpower deployment and nature of working environment. Application of fuzzy cognitive system is imposing responsibility to train the operator suitably so that they can identify the problem during operation locally and can correlate the factors identified for solving the problem automatically.
\end{abstract}

Keywords: Fuzzy cognitive, reliability, questionnaire, mapping

\section{Introduction}

The study of Grenaidy etc (2005)[1] reveals that mechanization of industries with the perspective of application of earth moving and plant machineries capable of operating the system with minimum effort from the viewpoint of operator and increasing adaptability of changing production requirements .The production demand is a variable factor and the target is being set keeping in view of customers' demand globally and the production target of various steel plants within and outside the country. Human reliability assessment meant for the purpose of evaluating the probability of human error occurring throughout the completion of a specific task. From such analysis adequate resources can be taken to reduce the likelyhood of errors occurring within a system and therefore lead to an improvement in overall levels of safety as observed by Hollnagel .E (1998)[2]. Human reliability assessment can be categorized in three streams like error identification, error quantification and error reduction .This inference taken from Stanton N.A, Salmon N.A. and Baber C \& Jenkins D.P.,2005[3] Appropriate network of information technology focused on the problem areas and giving solution for variables on constraints of factor of production, manufacturing machineries or outsourcing where it is necessary to adopt the solution or information arrived at .Thus information and communication technologies play a great role in modifying the systems' environment and modalities of work which can be applied to error detection, quantification and reduction.

Production in an opencast mechanized iron ore mines require an integrated approach regarding the comparable capacity mining machineries. Production planning begins from excavation ,haulage of the lump to plant, sizing of the ore by crushing, screening to appropriate mesh sizes for final despatch .The technical problem involve loading at downhill plant site of the enriched, sized and sintered iron ore of appropriate sizes to steel plants or to the nearest port for the purpose of exportation simultaneously reducing the lead time for delivery schedule .The mines planning should be effectively coordinated with the plant operation, spare parts supply and workers participation for motivated and cognitive ends. The present day production is actually knowledge based system which demands consciousness about the operational hazards about the heavy earth moving machineries. Machineries consist of $6.3 \mathrm{cu}$. meter capacity excavators, 80 tons dumper truck and more than 2500 tons/hour capacity of crusher in O.C.S L plant connected with the downhill screening plant by conveyor belt with automatic speed control system of more than $2.5 \mathrm{~km}$ in length. Reliability is an important factor in the mechanized mines as the dependence of the operator is increasingly on the heavy earth moving 
machineries which are required to give continuous operation among the iron ore dust which is very sticky and corrosive substance. The purpose of this mechanized system is to envisage production economy and the training of the operator is primarily based on the preventive and overhauling depending on the man machine interaction to optimize the production or achieving the production schedule. System of parallel machining line and coordinated multiple operation line followed to ensure reliability in O.C.S.L operations. As already discussed large capacities of mechanized mining machineries deployed to increase the productivity and workers engazed to operate these machineries in difficult mining environment .Many authors applied human reliability quantification method such as THERP,HEART,MEDA,JHEDI, HEROS etc with the aim of facilitating comprehensive and accurate assessment of the human contribution to ensure safety via dialated task and error analysis, quantification and practical error reduction ( B,Kirwan 1997[4], Rankins etc 2000[5]; Richie et al 2001)[6]) .Such technique permits to determine the facts contributing to human error and take corrective actions to eliminate/reduce the similar occurrences in future operations. Failure probability of a system component may vary with changes in weather, environment and operating conditions in mines (Feng, Woo, Zhang 2009 ) [7] where the Human Error Probability can also vary to changing conditions as follows: HRP = K1.K2.K3.K4.K5 ( Laurids Boring Ronald, 2008)[8]

$\mathrm{K} 1$ :Primary failure rate of work in progress of excavation

$\mathrm{K} 2$ : Available time for work in progress

$\mathrm{K} 3$ : Operators skill and training for on job experience

$\mathrm{K} 4$ :Operator,s fatigue in mines

K5: Ergonomical characteristics like noise, vibration, Illumination and postural conditions.

In course of analysis it is necessary to identify which factors describe the behaviour of the systems and estimate how much the variation of one of the facts reflected in the cognitive system. Lee etc,(1998)[9] first formalized about facts which affect the utilization of the machine most and the authors listed and classified the literature evaluating human errors and their effect on system performance. Many authors became interested following the first study, in characterizing the main factors affecting performance of industrial systems and in particular the performance of man-machine utilization. Kekuland and Svenson (1997) [10] explored the connection between work related factors, human errors and work performance in highly complex ,risky industrial systems .They affirm that work performance quality and safety are strictly linked to work related factors such as work environment, work demand, job supervision, job complexity, task loading and organizational factors. Also Basra and Kirwan(1998)[11] carried out research work on human error in offshore systems, outlined data collection methods, and provided selections of the human error probabilities generated as result of the study .In addition Chadwell et ;al(1999)[12] investigated the contribution of human factors in prevention of accidents in oil industry, in particular the U.S. Petroleum refining industry. The authors aimed to understand the causal relationship of human factors with safety and accidents in order to minimize human effectors as potential causes of accidents. The main results of the Chadwell's study prove that $47 \%$ of the cause identified involved elements of human factors. This value interpret that human factors deserve serious considerations when identifying areas for risk reduction and less prevention efforts. Present paper aims at projecting the Fuzzy Cognitive Mapping (FCM) of the mechanized mines based on reliability factor of man and machine utilization .The area of interest covered in the paper may be indicated as follows : (1) Concepts of FCM in the reliability perspective. (2)Man-Machine interaction in mining - effective mechanization (3)Fuzzyfying the input factors for the purpose

(4)Identification and rating of the factors

graphically after defuzzifying the output

(5)Result analysis and decisions

(6) Conclusion

1.1 Concepts of $\mathbf{f c m}$ in the reliability perspective : Cognitive maps (CM) were introduced by Axelrod(1976)[13] in the 1970s in order to develop and study social scientific knowledge in the field of decision making in activities related to international politics. CMs are signed diagraphs to represent the causal assertions and belief of a system of a person or group of experts with respect to a specific domain, and use that statement in order to analyze the effects of a certain choice on particular objectives. CMs are realized to use two types of elements : 1concepts and 2 causal belief. Concepts represent the variables used to describe the belief system of a person, whilst the causal belief consists of the causal dependencies between variables. Such variables can be continuous, ordinal or dichotomous.

2.0 Axelrod (1976)[ proposed two different types of FCMs: functional cognitive maps that simply allowed to represent the belief system of a person and weighted system or signed cognitive maps..In signed cognitive maps ,each relationship is linked to a sign that represent the sense of causal influence of the cause variable on the 
effect variable. Fig 1 shows a graphical representation of weighted cognitive maps in which the nodes are variable concepts and the edges are causal connections.

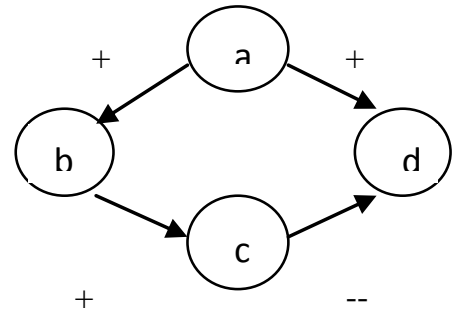

Fig 1

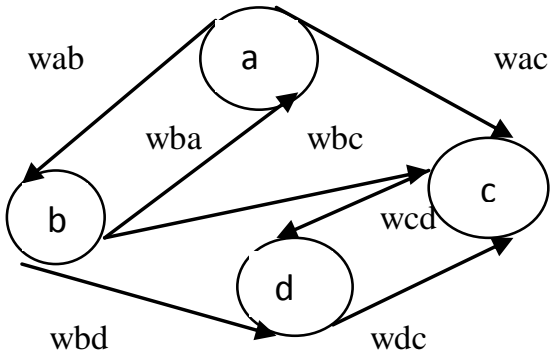

Fig 2

If the edge from node a to $b$ is positive, an increase or decrease in 'a 'causes a change in the same direction in' $b$ '.In case the relationship is negative i.e. an increase in ' $a$ ' causes any decrease in the value of ' $b$ ', the change that effect the variable is in the opposite direction .With cognitive maps, only centrality of concepts, and the direction of the effects of one concept to another concept can be analyzed .Now total effect of a cause variable $\mathrm{x}$ on effect variable $\mathrm{y}$, denoted by $\mathrm{T}(\mathrm{x}, \mathrm{y})$, is the sum of all the indirect effects from all the possible paths connecting $\mathrm{x}$ with $\mathrm{y}$. Therefore in Fig1, total effect of ' $\mathrm{a}$ ' on ' $\mathrm{d}$ ' is the sum of two indirect effects along Path P1(a.b.,c,.d) and along the pathP2(a,d).As both $\mathrm{P} 1$ and $\mathrm{P} 2$ are positive ,so $\mathrm{T}(\mathrm{x}$, y) is positive.

2.1Fuzzy cognitive maps(FCM) introduced by B. Kosko (1998)is an well-established artificial intelligence technique that incorporates ideas from artificial neural network and fuzzy logic.FCM extend the idea of cognitive maps by allowing the concepts to be represented linguistically with an associated fuzzy set rather than requiring them to be precise .In order to describe the degree of relationship between concepts it is possible to use a number between $(0,1)$ and $(-1,1)$,or use linguistic terms, such as "often", always", "some", "a lot", etc; Besides as each node(variable concept) is a fuzzy entity, it can be excited in different measure from $0 \%$ to $100 \%$ The representation in Fig 2 illustrates different aspects of the behaviour of the system showing the sequence of working network with forward completion of path as well as backward propagation .The requirement of hidden layer may be considered for necessary step by step activity retracting backward correction monitored in the hidden layer comparing with the supervised learning system. This can be represented by 'wbc' as the hidden layer while the path can be retracted after reaching the node point $\mathrm{C}$. The interconnection strength between two nodes $\mathrm{Ci}$ and $\mathrm{Cj}$ is wg€(-1,1) in the present study.

The types of causal relationships possible among the $\mathrm{f} \mathrm{c} \mathrm{m}$ concepts are

- $\mathrm{W} g>0$,positive causality between concepts $\mathrm{C} \mathrm{i}$ and $\mathrm{C} \mathrm{j}$

- $\mathrm{W} \mathrm{j}<0$, negative causality between concepts $\mathrm{C} \mathrm{i}$ and $\mathrm{C} \mathrm{j}$

- $\mathrm{W} \mathrm{g}=0$,no relationship between concepts $\mathrm{C} \mathrm{i}$ and $\mathrm{C} \mathrm{j}$

- From the figure 2, in FCM approach we can find the effect of 'b' on "c' as the total effect three path considering backward correction between point to point as $\mathrm{T}(\mathrm{b}, \mathrm{c})=\max \{11(\mathrm{~b}, \mathrm{a}, \mathrm{c}), 12(\mathrm{~b}, \mathrm{c}), 13(\mathrm{~b}, \mathrm{~d}, \mathrm{c})\} \quad$ Equation ( 1)

Now the value of each concept is calculated computing the +ve or -ve values of other concept to the specific concept.So starting from the basic concepts wab we can calculate the other concepts by adding or subtracting vectorially and mathmetical expression for it :

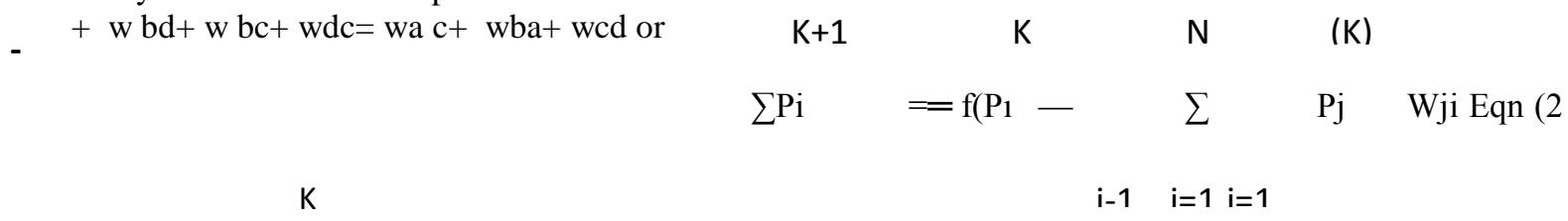

Where $\mathrm{Pi}$ being the value of the concept $\mathrm{Cj}$ and iteration step $\mathrm{k}, \mathrm{PI}$ the value of the interconnected concept $\mathrm{Cj}$ at the iteration $\mathrm{k}-1$,Wij the weighted arc from $\mathrm{Ci}$ and $\mathrm{Cj}$ and $\mathrm{f}$ a threshold function. Normally two threshold function can be used as such restricting the values within $(-1,1)$ The initial values of each of the concepts of the input vector and the weighted areas are set to specific values based on the mining project expert's belief. Applications of FCM have been developed in some industrial sectors :associated to simulation in order to present different future perspectives and thus decide possible alternatives(Kardaras and Karakostas 1999)[14]: , associated decision support system tool(DSST)(CHUNG et al 2002[15],Warren,1995)[16]in reliability studies particularly for methodologies in complex system(Bowles and Pelaez, (1996 )[17]for the 
modeling of the intelligent control system (Groumpos and Stylios,1999)[18] and Denham L Phipps, George H Meakins and P.C.Beatty[19] in extending hierarchial tasks etc;

\section{FCM for processing reliability analysis}

This analysis can be carried out by optimising the machine availability at mines and at plants for mining and processing of ore from the operational failure analysis in the past for mapping the cognitive requirement at a glance. The factors to be identified by group of experts through questionnaire and brain storming sessions .Fuzzy cognitive systems is base on If Then rule and it could connect multiple input variable. FCS could be utilized as a forecasting model when input/output data has some uncertainties. Fuzzy cognitive system therefore provide flexible way for recognizing their effective factors and modeling them. Input variables are fuzzyfied by the fuzzy membership functions and they are linked up with fuzzy cognitive system. In this system fuzzy expert's knowledge about failure detection is converted according to cognitive mapping scale as pointed out in the rating of our symbols and graphs. Fuzzyfying inputs are assessed by fuzzy inference system and finally output or detection scale is defuzzifier. Defuzzy output is a measure of corrective score. First input data should be fuzzified and their membership degree to be determined. For all the entries of input variable except environmental factors, triangular and trapezoidal membership function has been used in the actual processing.

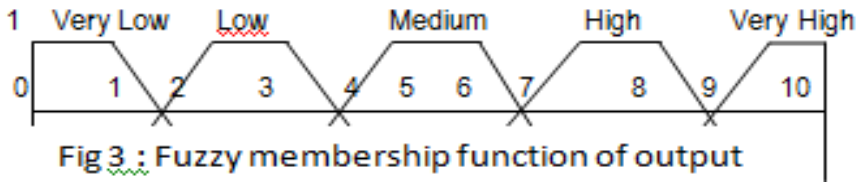

In case some of the values exceeds the threshold value of its concept, the value of the concept concurring the element is turned one in Fi for $\mathrm{i}=1,2,3 \ldots \ldots \ldots$. The threshold values are cut off points which will decide about the kind of relationship will be applicable in case of any two of the concepts will be active or inactive through a sigmoid function. A sigmoid function is used as

Fij $=11$ where Fij is the threshold value of the jth concept .xi are the normalised

value of domain variable $x i$ and eij a weighted link between $i=1,2 \ldots n \quad \& \quad j=1 \ldots n$
Threshold values indicate how much active are the concepts at any time Equation (3)

$\mathrm{e}$

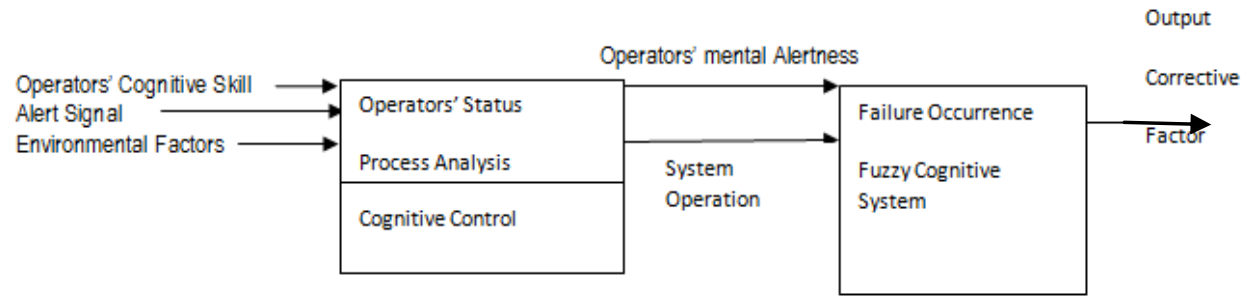

Fig 4: Fuzzy cognitive factor analysis

3.1 Major factors in operational reliability analysis : In our analysis for collection of datas number of experts restricted to ten and they may be regrouped to four heads as DM1,DM2,DM3 and DM4..The process involved questionnaire on functions, document analysis, group discussions and statistical probabilities to justify the datas. Among the factors study of production at mines and at plant including automatic control of entire crushing, screening or loading plant from control panel by single operator at each stage needs considerable mental alertness .Similarly major overhauling of capital equipments, availability of rapid consumable items as well as vital spare parts. Experts opinion covers training schedule of operators 'and maintenance crews, automatic handling mechanisms at various stages of production, run of mines(R.O.M) and actual availability of ores' at the crushing plant dumper platform, $\%$ of fines in the sized lump and safety status at mines and at plants .The availability of enriched ore of more than $65 \%$ iron content in large scale deposits is primarily an essential factor. But from the production angle the other important factors are 1 Increasing capacity of blast hole drills 2 Regular availability of heavy earth moving machineries (HEM) in operational condition 3 Equivalent plant capacity in comparison to R.O.M and processing to appropriate sizes of lumps and fines 4 Efficient transfer mechanisms and PLC system to monitor the handling and transfer hazards 5 Integration of overall maintenance planning at both mines and plants for uninterrupted production including materials procurement planning, inventory control practices and supply chain management at comparatively cheaper price. The job involved 30 days of mines and plants visits of experts for carrying out observations and finalized reading .The important human factor related with the study involved power and water supply at an altitude of $3000 \mathrm{ft}$ or more as seen from the study of conceptual and ergonomically perspective of health problem(Massimo Bertolini,2007)[20] .Thus chance of 
accidents, human reliability, work efficiency and work load are the important F.C.M factors(Melchers and Stewat,1997) [21].These are the factors also analysed by Torizuka (2001)[22].Causal nature of integration among human and technical factors from the viewpoint of productivity and from safety practices projected in the study of Shorrock and Kirvan (2002) [23],Sorensen(2002)[24]The attributes related to safety culture and organisational factors also studied by Latorella and Prabhu [25]. Notations used by us for representations of various states of human factors in connection with plant operations and mines productions are produced in the form of a table to conceptualize the factors as shown below in table 1.In order to characterize the data and factors linked to human behavior, the safety analyst must acquire deep knowledge of the work domain where the control and management activities related to the system examined are to be carried out. Stewart and Melchers[21] pointed out that such knowledge is obtained through three specific investigations (1) Visits to the plant and control unit during which discussions take place and data collecting questions and given to operator. (2) Review of the information provided by safety reports and projects for plant control and protection system. (3)Examination of the procedures and tasks of plant control operators ,both normal and accidental conditions( i.e. tasks analysis ) .In the actual processing four experts engaged and each of them had to indicate fuzzy linguistic terms to weigh the strength of all causal connections. Taber(1991)suggested a relation to unify the different judgment of experts based on the credibility weight of each expert. So the union of different judgments is obtained through the following equations:

$\mathrm{Fw}=\sum$ Fi. Wi where Fw is the Global FCM that reemploy the knowledge, Wi is the credibility weight of expert $I=1 \quad i$ is

Equation (4)

the single FCM of expert i. In our application ,each expert had the same credibility, so the relation proposed by Taber became the mean of fuzzy triangular numbers proposed by the panel of experts as discussed in 3.3 and table 2.

\begin{tabular}{|c|c|c|c|c|}
\hline category & symbol & Description & Factors related to operation & Remark \\
\hline & A1 & Reliability of System & $\begin{array}{l}\text { For Heavy earth moving mining, crusher, } \\
\text { screening and loading system by single } \\
\text { operator }\end{array}$ & $\begin{array}{l}\text { Uninterrupted } \\
\text { production }\end{array}$ \\
\hline \multirow{7}{*}{$\begin{array}{l}\text { Psychological } \\
\text { Factors ---- } \\
\text { A }\end{array}$} & $\mathbf{A 2}$ & Multiple Activity through & Crushing, Screening and Loading & ---Do--- \\
\hline & & Control & & \\
\hline & & Panel by Single operator & & \\
\hline & A3 & Chance of error & $\begin{array}{l}\text { Material handling /belt over speeding } \\
\text { /rupture and pollution }\end{array}$ & ----Do-- \\
\hline & A4 & Difficulty of Operation & $\begin{array}{l}\text { Heavy duty operation ,Transfer from } \\
\text { stockpile and break down problems }\end{array}$ & $\begin{array}{l}\text { Human\& machine } \\
\text { Safety }\end{array}$ \\
\hline & A5 & Mental Distraction/hazards & Hazardous environment \&multiple activity & -----Do--- \\
\hline & F1 & Continuous operation & Physiological and psychological & Needsl \\
\hline \multirow[t]{3}{*}{$\begin{array}{l}\text { Physical } \\
\text { factor--F }\end{array}$} & $\mathbf{F} 2$ & Complex Task & $\begin{array}{l}\text { Heavy duty excavation and down hill } \\
\text { transportation by conveyor belt. }\end{array}$ & Skill and Effort \\
\hline & $\mathbf{F 3}$ & Handling of Task & Physical strength to carry out maintenance & Perceptual part \\
\hline & W1 & $\begin{array}{l}\text { Incomplete } \\
\text { layout/construction }\end{array}$ & Major Overhauling and high R.O.M & Automated line \\
\hline \multirow{3}{*}{$\begin{array}{l}\text { WORK } \\
\text { SPACE } \\
\text { WITHIN } \\
\text { PLANT---W }\end{array}$} & W2 & Insufficient Space & $\begin{array}{l}\text { In same space handling of two machines } \\
\text { restrict5ed }\end{array}$ & ----Do--- \\
\hline & W3 & Inaccessibility to machine & Automated line and HEM & ------DO--- \\
\hline & E1 & Noise level > 80 Decibels & Machine operation-switch mode/control & $\begin{array}{l}\text { Sufficient Light and } \\
\text { Ventilation } \\
\text { arrangement }\end{array}$ \\
\hline \multirow[t]{2}{*}{$\begin{array}{l}\text { Environment } \\
----E\end{array}$} & $\mathbf{E 2}$ & & $\begin{array}{l}\text { Mines visibility very poor during rains and } \\
\text { fog and road accidents are more. }\end{array}$ & $\begin{array}{l}\text { Wet iron ore is very } \\
\text { corrosive. }\end{array}$ \\
\hline & $\mathbf{E 3}$ & Vibration & Robust foundation & Robust Design \\
\hline \multirow{2}{*}{$\begin{array}{l}\text { Machinery/to } \\
\text { ols M }\end{array}$} & M1 & Heavy Duty & Training\& skill and effort & Perception level \\
\hline & M2 & Control & Cognitive and repetitive & Should be high \\
\hline \multirow{3}{*}{$\begin{array}{l}\text { Communicat } \\
\text { ion }\end{array}$} & C1 & Machine Breakdown & Regular Feedback & High response \\
\hline & $\mathbf{C 2}$ & Wrong Information & Effective Monitoring & $\begin{array}{l}\text { Checking } \\
\text { Parameters }\end{array}$ \\
\hline & C3 & Supervisory Efficiency & Experience Based & Cognitive \\
\hline
\end{tabular}


Prediction P Forecasting and Planning Integrating Man and Machine Operation Cognitive and Scheduling As the study is based on trouble free operation viewpoint experts considered factors from the records for mean time between two successive failures and on the basis of brainstorming in a few sessions. The linguistic terms used against different factors within indicator(-1,1) and the range of symbol categorized from very low to very high in the following manner : 1 Very low (VL) -0,1,3 2 Low(L)-2,3, 5 3.Medium(M) - 4, 5, 6 $4 \mathrm{High}(\mathrm{H}) 6,7,8$ and 5 Very High $(\mathrm{VH}) 8,9,10$,Experts ranked each of the factors on the basis of four alternatives as par mapping of factors in table 2 and the representative decision model proposed by them. The decision model again associated with fuzzy numbers ranked successively from 1 to 10 index identifying characters as graphically presented in table 2 scaling the attributes in Thurstone Scale (26). The model is multiplied by weight age factors developed on the basis of ranking from ( 0 to 1$)$ in the linguistic terms. This is to be developed after consultation among all the Group of Experts after comparing the result with physical impact of the factors comparing them with the records.

Table :2 Fuzzy Inference of Human Factors (Ranking as per Thrustone Scale (1 to10 ) Human Factor Component of the factors DM1 DM2 DM3 DM4 Weighted Mean Squared Value

A1 Reliability

A2 Multiple Activity

A3 Chance of Error

A

A4 Difficulty of
operation

A5 Mental Distraction

5

7

F1 Continuous Operation

F

F2 Complex Test

F3 Handling of Task

W1 Incomplete Construction

W2 Insufficient Space

W

W3 Inaccessibility

E1 Noise Level

E

E2 Visibility

E3 Vibration

M1 Heavy Duty

M

M2 Control

C

C1 Machine Breakdown

C2 Delayed Supply /In correct Info .

C3 Supervisory Control

$\mathbf{P}$

Forecasting and Planning

\begin{tabular}{ccccc}
9 & 7 & \multicolumn{2}{c}{7.5} & 8 \\
9 & & 6 & 8 & 8 \\
3 & 1 & 3 & 1 \\
7 & 6 & 7.5 & 5
\end{tabular}

5.96

5.50

35.52

30.25

0.25

4.21

11.22

\subsection{9}

16

6.76

45.69

7.95

18.49

36.60

21.16

6.25

27.82

1.21

44.56

62.0

7.875

4.0

16

1.025

1.05

6.05

36.60

7.8

57.78 
Table3 Weight age decided by the experts for linguistic mapping

$\begin{array}{lll}\text { Very High } & 0,8,0.9,10 & \text { Higher Performance } \\ \text { High } & 0.6,0.7,0,8 & \text { Significant } \\ \text { Medium } & 0.4,0.5,0.6 & \text { Aver } \\ \text { Low } & 0.2 .0 .3,0.4 & \text { Fair } \\ \text { Very Low } & 0,0,0.1,0.0 & \text { Insignificant }\end{array}$

Table 4 : Mapping of Fuzzy Decision Values

\begin{tabular}{|c|c|c|c|}
\hline Normalized Value & $\begin{array}{l}\text { R.M.S Value of } \\
\text { Factors }\end{array}$ & $\begin{array}{l}\text { R.M.S } \\
\text { Error }\end{array}$ & Remarks \\
\hline \multicolumn{4}{|l|}{5.96} \\
\hline 5.50 & & & $\begin{array}{l}\text { Mechanized } \\
\text { System Error }\end{array}$ \\
\hline 0.50 & $A=4.266$ & 1.985 & Possibility \\
\hline $\begin{array}{l}4.21 \\
2.7\end{array}$ & & & Insignificant \\
\hline 4.0 & & & Effective \\
\hline 6.76 & $F=4.81$ & 1.65 & Maintenance of \\
\hline $\begin{array}{l}2.82 \\
4.3\end{array}$ & & & $\begin{array}{l}\text { Parallel line of } \\
\text { Plant operation }\end{array}$ \\
\hline 6.05 & $W=5.04$ & 0.785 & Minor \\
\hline 4.6 & & & Effect \\
\hline \multicolumn{4}{|l|}{2.7} \\
\hline 5.275 & $E=3.43$ & 1.72 & $\begin{array}{l}\text { Maintainability to } \\
\text { be }\end{array}$ \\
\hline 1.1 & & & Improved \\
\hline 6.675 & $M=5.86$ & 0.601 & Minimum Effect \\
\hline 7.875 & & & On Performance \\
\hline \multicolumn{4}{|l|}{4.81} \\
\hline 1.025 & $C=4.50$ & 3.70 & Significant \\
\hline 6.05 & & & Result \\
\hline
\end{tabular}

3.2 : The relational value to be determined after ranking the factors in terms of linguistic terms like very good or bad within the span 1 to 10 and to be multiplied by weight age to the factors ranking them as per table 3 of the four ratings. The weighted mean calculatedasA1(5.95).A2(5.50)A3(0.5),A4(4.21),A5(2.7),F1(4),F2(6.76)F3(2.82)W1(4.3),W2(6.05)W3(4.6),E1( 2.7),E2(5.27),E3(1.1)M1(6.67), $\mathrm{M} 2(7.87) \mathrm{C} 1(4.81) \mathrm{C} 2(01.025), \mathrm{C} 3(6.05) \mathrm{P}(7.8)$. The ranking of the factors on the basis of High to Low done on priority by brainstorming session and the Decision ranking Method applied against each to get the result on assessment in terms of selection of fuzzy numbers of single digits within the value 1to 10 . The weighted result and the root mean square value calculated against each as shown in the FCM TABLE.4.R.M.S value of the factors and corresponding error analysis helps to identify different areas where necessary improvement can be done.

4.0 Results and discussion: The decision model analyzed considering cognitive environment in a mechanized mine where the activities analyzed elaborately considering both mining and plant operations. From the nature of factors the analysis has been carried out to identify whether the factors are in favor of production or simply adverse in nature to reduce the speed if proper care is not being taken Some of the factors will not directly influence the production as these are primarily based on construction. The resource to be invested for the purpose of improvement of the adverse factors. Accordingly the factors mapping done presenting the corresponding value for improvement. Depending on the demand of the job necessary iterations to be increased for deciding further about the criticality of the existing ratio. The maximum effect found on machine and tools with R.M.S value 5.86 but minor error 0.601.But the psychological factors and communication is found of paramount importance with corresponding R.M.S values 4.50 and 4.266 respectively .Effect found on noise level and vibration which is 3.43 with R.M.S error1.72.. Regarding mapping of the diagraphs nthe multiplicative value e. g; A1A2 $=33$ which is favorable represented by + and F2E1 =-- 18.25 which represents against productivity and is a factor adverse to productivity. The sound of heavy earth moving machinery may be the cause of such disturbances which is very effectively minimized .But the production level to be maintained by gyratory crusher where production is controlled through control system and have informatio0n level of all subsystems in the plant controlled cognitively .Pollution due to iron ore has direct effect on the operator, worker, miner and plant maintenance staff during summer and rainy season which means it is seasonal. 


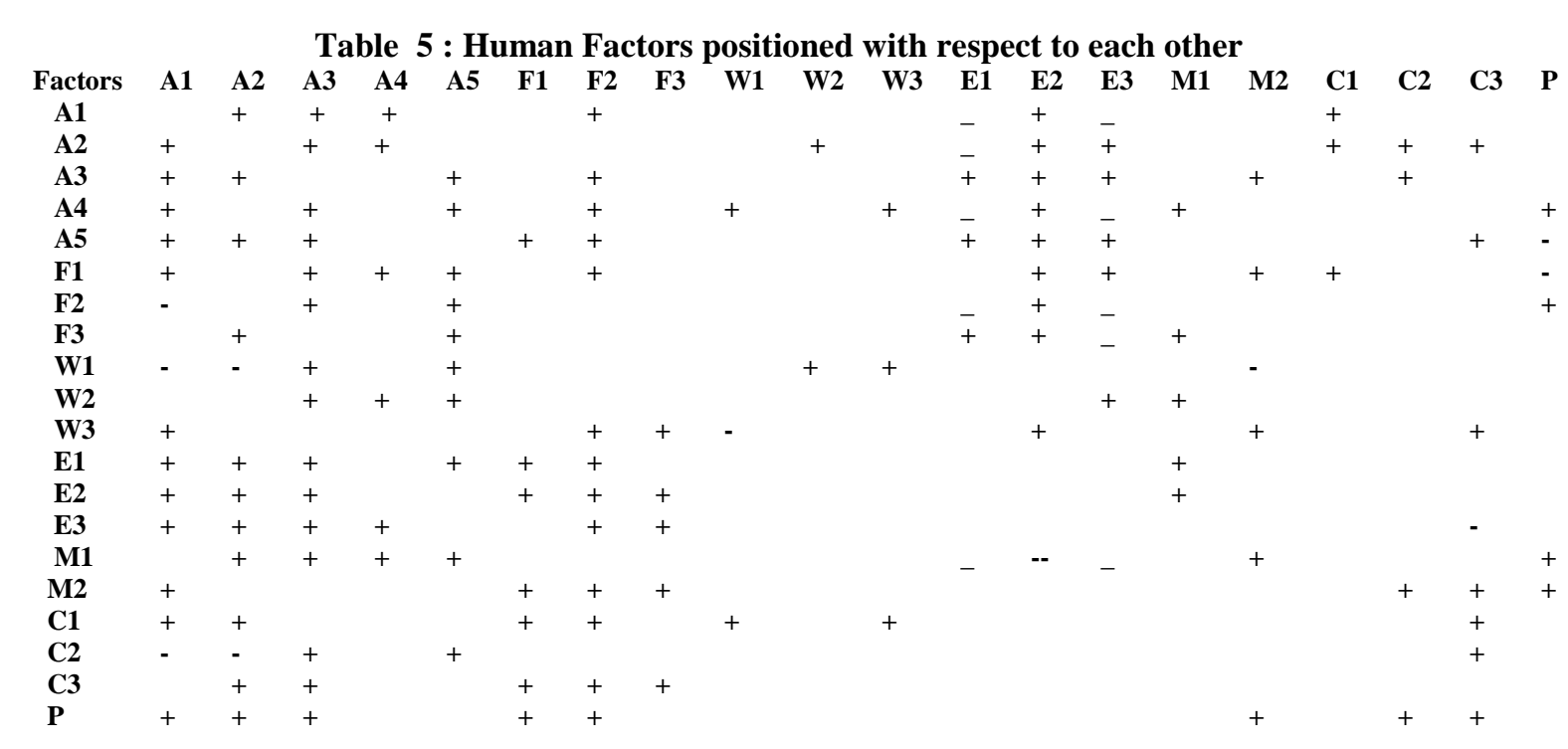

\section{Conclusion}

The result obtained as shown above analyzed for decisions to improve the production and maintenance of mining and plant machinery .From the value of R.M.S. error it points out that the mechanization is advanced and the chance of any failure can be diagnosed as error in mental alertness is being controlled following the experts assessment in this regards. From the error analysis it has also been observed the \% difference is more in environmental or situational decisions particularly in climatic condition. Besides preventive maintenance and supervisory control are the two other field where control is to be exercised and monitoring of the failure should regularly be checked from the history sheets of failure of important machineries. Supply of power, fuel and servicing geared up to match the production requirements in adverse weather during rains when the visibility is poor. The decision to be taken further to evaluate heavy duty machineries availability during critical situation to balance the factors optimizing the production level. Special training should be provided to skilled and unskilled operator and worker increase production through effective maintenance .

\section{Acknowledgement}

This paper is the result of consistent effort of myself and the mining authorities of National Mineral Development Corporation who guided about the problems of opencast mines and the systems and technologies to overcome the technical and human factors provlem related with mines production. I am also very grateful to my professors and Head of the department of Production engineering department who helped me consistently. Besides the paper is the result of advise of my advisors Dr Debamalya Banerjee and Dr Surojit Ghosh of Jadavpur Univeraity, Production.Engineering Department. Besides Dr D.K.Biswas and other faculties of Mallabhum Institute of Technology actively helped me for the fulfillment of the paper.

\section{References :}

[1] Grenaidy A, Karowsky,W,Shell R.A ,khalil S, S Tunal's etc;(2005)Work compatibility of an integrated diagnostic tool for evaluating musculoskeletal responses to works and stores outcomes, International journal of industrial ergonomics ,35,1109,-11312

[2] Hollnagel E(1998): Cognitive Reliability and Error Analysis Method-CREAM Oxford ,Elsevier ,Science

[3] Stanton ,N.A. Salmon, P.M. Walker, G.H .Baber ,C \& Jenkins, D.P (2005) Human Factors Method ,A practical Guide for Engineering and Design, Ashgate : Aldershot

[4] B.Kirwan and L.K,Ainsworth :A guide to task analysis ,published by Taylor and Francis Group

[5] Raskin Jeff ,Oct 2000,:The Human Interface -New Dimensions For designing interactive systems, Published \& sold by Amazon.com

[6] Ritchie J and Spencer L (1994): Qualitative Data Analysis for applied policy research, in A.Bryman \& R.G.Burgess (eds) Analyzing Qualitative data ,1994,pp173-194

[7] Feng Yongquing, Wu Wenchuan, Zhan Boming ,Li Wenyuan, 'Power systems operation risk assessment Using Credibility theory ,IEEE Transactions on Power systems, Vol 23,No 3,2008

[8] Laurids Boring Ronald (2009) : "Human Reliability analysis in Cognitive engineering and system design " Sandia National Laboratories 'New Mexico

[9] Lee K,W, Tillmann F, Higgins J,J (1988) A literature survey of the human reliability component in a man machine system,IEEE Transactions on reliability, 37(1),24-34.

[10] Kekuland L.J.\& Svensen O(1997) :Human errors and work performance in a nuclear power plant control room; associations with work related factors and behavioural coping , Reliability engineering and systems safety $56,5-15$.

[11] Basra and KIRWAN,1998G Basra and B.Kirwan: Collection of offshore human error probability data,Reliability Engineering and System Safety 61(1998)pp 77-93 
[12] Chadwell et al 1999 Chadwell B Levereen,Jr,F.L.Rose,S.E.1999 Contribution of human factors to incidents in the petroleum refining industry, $33^{\text {rd }}$ Annual Loss Prevention System Symposium ,American Institute of Chemical Engineers ,Houston Texas,U.S.A

[13] Axelrod,(1976): Structure of decisions, Princeton University Press , Princeton ,N.J,

[14] Kardaras D and Karakostas B,1999 :The use of cognitive maps to stimulate the information systems strategic planning process, Information and Softwarew technology,41,197-210

[15] Chung et.al2002H Chung,K.C.Lee,J.S.Kim and S. J .Know ,Fuzzy Cognitive Map Approach to mining inference amplification.Expert System with application 22(2002),pp 197-211

[16] Warren K ,1995,Exploting competitive features using cognitive mapping, Long Range Planning

[17] B. Bowles and C.E.Pelaez, using Fuzzy Cognitive maps as a system model for future models and efforts analysis, Information Science 88 (1996) pp 177-199

[18] Grumpos and Stylios,1999,PPGrumpous and C.D. Stylios. A Soft Computing approach for modeling the supervisor of manufacturing system, Journal of Intelligent and Robotic Systems 26, pp 389-403

[19] Denham L Phipps, George H Meakin and Paul C W Beatty : Extending hierarchial task analysis to identify cognitive demands and information requirements, Applied Ergonomics 42 (2011),pp 741-748

[20] Massimo Bertolini - (2007May) : Assesment of human Reliability factors, A Fuzzy Cognitive Map Approach , International Journal of Industrial Ergonomics ,Volume 37,Issue 5 ,pp ,404-413

[21] Melchers, R.E , Steward G,1997: Probabilistic Risk Assessment of Engineering System , Chapman and Hall London

[22] Toriizuka ,T.,2001 : Application of Performance Shaping Factors (PSF) for work improvement in industrial Plant Maintenance Tasks,International Journal of Industrial Ergonomics, Vol 28 ,pp225-236

[23] Shorrock , S .T.,and Kirwan B., (2002) Development and Application of a human error identification tool for Air Traffic Control ,Applied Ergonomics Vol $33,319-336$

[24] Sorensen,J.N, (2002) Safety Culture : A survey of the State of the Art Reliability Engineering and Systems Safety, Vol 76, pp189204

[25] Latorella, A and Prabhu P.V.,(2000) : A review of human error in aviation maintenance and inspection.International Journal of Industrial Ergonomics, Vol $26,133-161$

[26] Leandre R Fabrigat \& J. Shelly Park: Thurstone Scales,Encyclopedia of Measurement and Statistics, Sage Research Methods,Neil J Salkind \& Kristin Rasmussen ,Publication date 2007,Print ISBN : 978141296110. 